\title{
Complex Vaulted Systems: Geometry and Architecture from Design to Construction
}

\section{Roberta Spallone $^{1}\left[\right.$ Marco Vitali $^{1}$ (])}

Published online: 23 November 2020

(c) Kim Williams Books, Turin 2020

\begin{abstract}
Nexus Network Journal guest editors Roberta Spallone and Marco Vitali introduce the papers in vol. 22 no. 4, a special issue dedicated to Complex Vaulted Systems.
\end{abstract}

Keywords Vaulted systems $\cdot$ Geometry $\cdot$ Construction history

\section{Introduction}

In Western architecture, masonry and stonework vaults were the main structures used over the centuries for covering the interior spaces of buildings. In specific historical periods (e.g., the Middle Ages, the Baroque, even the Contemporary), vaults acquired particular complexity due to a significantly stringent link between geometry and architecture that fuelled the inventive abilities of designers and builders. The experimentation with and the construction of new spatial configurations favoured the virtuosic application of stereotomy to stonework and the enhancements of building techniques with masonry and concrete works. The study of vaulted systems involves an exploration into the relationships between geometry and architecture in the process from design to construction, dealing with shapes, materials, and ornamentations. The theme of this special issue encompasses complex vaulted systems over the centuries.

The issue of complex vaulted systems has been at the centre of the interests of the guest editors and their research group since 2012, when they undertook research focused on complex masonry vaults in Baroque civil architecture in Piedmont. Their studies range over the digital reconstruction of the sources (treatises, manuals, original drawings), the survey of Baroque buildings, the geometric and parametric modelling of both the ideal shape of the complex vaults and the as-built, and the

Roberta Spallone

roberta.spallone@polito.it

Marco Vitali

marco.vitali@polito.it

1 DAD - Dipartimento di Architettura e Design, Politecnico di Torino, Torino, Italy

Birkhäuser 
more recent experiments related to Artificial Intelligence (AI) and Augmented Reality (AR) aimed at promoting the built heritage and sustainable cultural tourism. Their research is still ongoing and the very interesting and multi-faceted contributions received as a result of the Call for Papers suggest that many other aspects need to be investigated. More importantly, multidisciplinary interests have emerged on the proposed theme, which it is hoped will foster new collaborations and exchanges of ideas among scholars. Above all, it is hoped that the essays presented here will lead younger scholars to conduct research on these topics, introducing new ideas, methodologies, and interpretations.

The Call for Papers for this special issue suggested four topics of interest: modelling of historical sources on vaults' geometry and architecture, comparative morphologic studies of geometrically-shaped vaults, analysis of geometric tracing, stereotomy, centring, and methods of calculation in the built heritage, and investigation of the relationships between geometry and structure in historicized vaulted systems.

The authors' responses to the call were distributed evenly over the four themes and even delineated a fifth: the relationships between geometry and architecture that link shapes, materials, and ornamentations, creating special illusory effects.

\section{Modelling of Historical Sources on Vaults' Geometry and Architecture}

The modelling of historical sources involves referring to archival, iconographic, and documentary sources, as well as to architectural literature (treatises, manuals, sketchbooks, etc.). The graphical analysis and recognition of geometry, proportions, and modularity entail actual survey work and are continuously intertwined with the hermeneutics of the texts, feeding each other new possible interpretations. Modelling the acquired data is complex work because it involves synthesizing the knowable data in a spatial object and hypothesizing the completion of data that were lacking. Moreover, the proposed model may be only one of different plausible coexisting interpretations. The result is a unique and original product that belongs to the field of ideal theories or reconstructions of artefacts that no longer exist. For this reason, modelling is affirmed to be a true heuristic method. Digital modelling tools offer new images of such buildings as three-dimensional objects and can become elements of reference to and comparison with the built heritage. With respect to precisely this last aspect, the studies can offer significant theoretical support to the analysis of built heritage, allowing the decoding and comprehension of the complex nature of vaulted systems.

The authors' contributions to this topic explore the works of Choisy and Paredes concerning conical barrel vaulting equipment, the stereotomic knowledge advances at the École Polytechnique, the architectural literature on stereotomic single-row spherical domes, and the reconstruction of geometry and stereotomy in the Halle au Blé's vaults.

"Brick Vaults by Slices in Choisy and Paredes", by Enrique Rabasa-Díaz, Ana López-Mozo and Miguel Ángel Alonso-Rodríguez, offers an in-depth analysis of constructive and structural features of conical barrel vaulting equipment that can be 
built without formwork, with reference to primary sources belonging to French and Spanish areas. The study relates texts and images from the main sources (by Choisy and Paredes) with different interrelated aspects of construction, such as bricklaying techniques, geometry, and structural behaviour. The analysis leads the authors to very interesting considerations about the intellectual distance between the Choisy and Paredes and allows them to verify that Paredes' concave cones are possible and his intuition about the better stability of these cones is correct.

Federico Fallavollita and Marta Salvatore, in "Stereotomy of Vaulted Systems of the École Polytechnique", investigate the contributions made by Gaspard Monge and the students of his school to the stereotomy of vaulted systems in France. The applications presented in the paper illustrate the contributions made by descriptive geometry, in terms of theoretical generalization, as the solution to stereotomic problems. These contributions show, on the one hand, the lively academic speculation of stereotomy and, on the other, its decline as an applied art. The authors analyse three cases, establishing a modus operandi that investigates shape in space, showing the power of theory through drawing. They sharply remind us that the main objective of descriptive geometry is the study of forms, their properties, and their spatial relations, and then affirm that this science can acquire renewed vigour today, thanks to digital representation.

"Single-Row Spherical Domes in Stereotomy Treatises", written by Pedro M. Cabezos-Bernal and Juan J. Cisneros-Vivó, offers a rigorous comparative study of the different solutions to the stereotomic problem of single-row spherical domes proposed by De L'Orme, Vandelvira, Dechales, and Tosca. The drawing and modelling in this essay are used for the three-dimensional reconstruction and verification of the stereotomic patterns studied. The results facilitate the comparison-in terms of spatial conception, geometry, tracing and distribution of the voussoirs, and construction-and simplify the understanding of the original drawings.

Agostino De Rosa, Francesco Bergamo, and Antonio Calandriello, in their paper "History, Geometry and Stereotomy in the Vaults of the Halle au Blé", conduct an interesting study that links some of the elements of the complex vaulted system designed by Nicolas Le Camus de Mézières with treatises, especially the work by Amédée-François Frezier. In fact, the new geometric and constructive issues by Le Camus de Mézières, assembled by means of blending stone and bricks, are recognized by the authors as reinterpretations, in a more complex way, of some of the stereotomic problems faced by Frezier. The study of construction events and geometric analysis, carried out through three-dimensional modelling, led the authors to hypothesize that the solutions adopted are the result of a decidedly more experimental approach to solving complex geometrical problems by approximations, based on close on-site collaboration with stonemasons.

\section{Comparative Morphologic Studies of Geometrically Shaped Vaults}

Comparative morphologic studies have as their object the built heritage and allow the recognition of models, imitations, recurrences and variations of a morphologic type, and variants and invariants of the components of the vaults. On the one hand, 
the vaulted systems are read through the theoretical lens of their geometric features; on the other, the architectural works are surveyed in their current condition. The geometrical analysis, with the recognition of the shape of the intrados surfaces, their generatrices, directrices, and main cross-sections, guides the survey activities and subsequent interpretations through drawings and models. This analysis takes as primary sources the original drawings and the contemporary architectural literature and must refer to the progress of scientific knowledge in the period and areas considered.

Moreover, the comparison between theoretical and surveyed shapes suggests a series of considerations, the most elementary of which concern the deformations, failures, and transformations that the vaulted system may have suffered over time. Other more complex observations refer to the passage - and in some cases the gapbetween conception and construction, which involves knowledge of the construction materials, centring structures, and laying techniques. It is precisely in this passage that the ideal model loses its strict geometric shape due to the constructive constraints.

The comparison between different buildings plays a decisive role in the identification of geometric models and in the construction of the links between each building to support historical and construction studies.

The contributions related to this topic deal with the following: the relationship between geometry and construction in selected case studies of eight-loop ribbed vaults, the geometric analysis and comparison of edge vaults in some buildings in Lecce, the hypotheses about design, stereotomy, and construction of transverse joints of ribless vaults, the tracing methods of warped vaults on stone stairways, and the methodological framework for the study of domes on the basis of different survey experiences.

Ricardo García Baño and Macarena Salcedo Galera, in "Geometry and Construction of the Eight-Loop Ribbed Vault", take as their starting point an articulated drawing found in the oldest stonecutting Spanish manuscript and investigate, following a clear and wellexposed methodology, the graphic construction in plan in its relations with tracing and construction. The quality of the drawing and the comparison with contemporary sources allow the authors to realize that, different from the custom in treatises, the drawing in question is most probably a drawing for use during construction and not a compositional scheme. Some confirmations of this hypothesis derive from a great work of census and survey that allows the authors to recognize in Spain at least twenty-nine starry vaults with eight loops - although not all of them strictly follow the scheme presented in the manuscript - and to identify, in the church of Garcinarro in Cuenca, several vaults that relate more directly to the tracing contained in the manuscript.

The work "Interpreting Lecce Vaults with Analytical-Geometrical Models", by Assunta Pelliccio and Marco Saccucci, presents an interesting study showing that the interpretative geometric models proposed in the literature do not fit real cases, presenting deviations and discontinuity in the intrados surface. The analysis and photogrammetric survey of several case studies allow the authors to reformulate the geometric hypotheses underlying the theoretical model, arriving at the formalization of a generalized geometrical model able to reproduce, with the assignment of four parameters, all the different types of the Lecce vaults. The intuition of the authors 
and the consequent refinement of the theoretical model are born from considerations related to the construction practices.

The essay "Transverse Arches in Spanish Ribless Vaults" by Pablo NavarroCamallonga raises the question of the transverse joints tracing in the ribless vaults. The author considers this topic to be central, not marginal, and considers it contemporarily and together with issues of geometry, stereotomy, and construction. Comparing several case studies, he concludes that ribless vaults can be considered a composition of transverse arches and discusses his hypothesis from a structural, constructive, and geometric point of view. This leads to a set of simplifications in the processes of conception and construction that help us understand the genesis of these particular works and pave the path toward new research fields related to structural behaviour.

Concepción López González and Rafael Marín-Sánchez, in their paper "Ashlar Staircases with Warped Vaults in Sixteenth- to Eighteenth-Century Spain”, survey, represent and compare three-section cantilevered stone stairways. These stairways, built along Spain's Mediterranean coast, are supported by vaults of complex warped shapes. The results obtained through the analysis attest to the existence of a formal control method for the vaults of these stairways not recorded in the known treatises. The process involves simultaneously handling elevation and plan projections to obtain the geometric centre of the curves that delimit these vaults. The simplicity and originality of the geometric procedure found by the authors rely on the use of dimensional references obtained from the stairwell measurements.

Carlo Bianchini, in "A Methodological Approach for the Study of Domes", offers an in-depth analysis of the changes produced in the methodologies of study, survey, and analysis of architecture in general and domes in particular thanks to the technological advances produced by the digital revolution in recent decades. He presents experiences of laser scanning and Structure from Motion (SfM) surveys of three case studies: Hagia Sophia in Istanbul, the church of St. Carlo ai Catinari in Rome, and St. Peter's Basilica in the Vatican City. Starting from the radical shifts in approach to the different stages of acquisition, selection and interpretation, representation, and communication, the author aims to structure, in a continuously and rapidly changing reality, methodologies and protocols of investigation and scientific research, linking the survey data, the analysis of shapes and geometries, and the structural behaviour and deformations.

\section{Analysis of Geometric Tracing, Stereotomy, Centring, and Calculation Methods in Built Heritage}

The built heritage is a treasure trove of applied knowledge that can be used to identify numerous aspects of architecture that are inextricably linked in construction. The study and analysis of the existing heritage are therefore configured as a process of "excavation"; starting from the survey data, currently conducted massively by means of laser scanners and/or digital photogrammetry, it is necessary to interpret the acquired data, group them into semantic categories and interpret their relationships in order to start a process of digital 
re-construction aimed at the discovery (or better understanding) of aspects related to geometric tracing, the application in the field of stereotomic theories, calculation methods used by designers to ensure adequate structural behaviour and pre-dimensioning of the main elements of the construction.

In fact, all the aspects taken into consideration are interwoven in relationships that connect the geometric tracing to the design idea. This leads to the realization of the work in a non-linear process that involves considerations concerning the diffusion of archetypes and design styles, the circulation and sharing of construction techniques and use of materials (also through treatises), on-site practices, and the life of the building. The articles related to this topic explore singular case studies or vaulted systems belonging to the same architectural complex.

These contributions regard the following: the proportioning, measurement system, and stone-cutting techniques in the Roman vault at Grotta dei Massacci, composition and relations between shape and structure of Hadrianic domes, geometric analysis of pitched-brick barrel vaults in the Egyptian fortification of Umm al-Dabadib, the relations between geometry and structure in the dome of the Escuelas Pías in Valencia, design and distribution of coffers in the dome of S. Bernardo alle Terme in Rome, and the geometric interpretation and 3D reconstruction of the frame vault of Villa Borromeo in Cassano d'Adda.

José Calvo-López, Giulia Piccinin, Pau Natividad-Vivó and Alessio Bortot, in their important contribution "The Roman Ashlar Groin Vault at Grotta dei Massacci", formulate some hypotheses about the measurement system, proportion, stonecutting technique, and hoisting systems used in the execution of a singular complex groin vault in the ashlar in Roman architecture. The authors, thanks to a rigorous laser scanner and photogrammetric survey, observe that the unit of measurement is the Roman foot, but cannot surely affirm the presence of other proportional schemes. Instead, they affirm that the most interesting issue is the division of the vault into voussoirs. They conclude that the voussoirs may have been shaped by the requirements of their definitive position, with masons working on the formwork, using the voussoirs in other courses to shape each voussoir at the most critical point, the intersection of cylinders. For this reason, this stone-cutting method does not require a preliminary tracing or the use of orthogonal projection, which seems to be absent in the Roman method used for formal control. Finally, they underline the fact that the weight of the stones and the hoisting equipment led to the need for specialized machines, such as those described in Vitruvius's Book X.

The paper "Composition and Shape of Hadrianic Domes", by Luca Cipriani, Filippo Fantini, and Silvia Bertacchi, deals with the design of the domes at Hadrian's Villa in Tivoli. Basing themselves on 3D surveys carried out with active and passive sensors and comparing horizontal and vertical orthographic projections of the analysed buildings, the authors find common elements and features. This allows them to hypothesize dimensioning systems of the vertical structures together with possible criteria for defining the intrados-extrados relationship. They cleverly conclude that Hadrian's architects used precise grid-based designs to facilitate the achievement of target quantities (required areas and volumes) as well as modules aimed at defining alignments of horizontal and vertical structures. The research 
provides useful elements for an integrated reading of the individual buildings to support the archaeological investigation.

Corinna Rossi and Fausta Fiorillo, in "The Vaults of Umm al-Dabadib: Geometric Study", carry out the analysis of the geometric shape of the pitched-brick barrel vaults of the rooms in an Egyptian fortification of the Late Roman Period in connection to ancient building techniques. Their geometric and metrological analyses rely on an accurate photogrammetric survey. Through the comparison of selected cross-sections of the rooms and the superimposition of geometrically different curves, the authors conclude that the directrix of the barrel vaults is an ellipse and hypothesize a simple and efficient construction technique for their realization, also taking into account the units of measure of the period.

The essay "New Contributions on the Escuelas Pías Dome in Valencia", by Pablo Rodríguez-Navarro and Teresa Gil-Piqueras, proposes an interesting study on this large single-shell brick dome from a geometrical-compositional and structural behaviour point of view. The geometric analysis was matured in close comparison with Fontana's 1694 drawings for the design and static analysis for the construction of a single-shell dome and its lantern. The comparison of the survey methods and the analysis of the results, in which the authors propose some hypotheses on construction techniques and structural behaviour, are particularly interesting.

Licinia Aliberti, in "The Vault and Coffers of S. Bernardo alle Terme in Rome", accurately explores the relationships between the geometry and construction techniques of a dome of Roman origin in opus caementicium, focusing on the design and distribution of coffers realized later. Concerning the general geometry of the dome, the author observes that its inner surface is indeed spherical and that it shows a zone of depression in the upper area. Regarding the alignment of the coffers, she highlights that their radial distribution is quite regular while their design is rather irregular, and that it is difficult to find horizontal alignments of these elements. Moreover, the study of the design of the coffers reveals that the connection between the transversal surfaces and the bottom levels of the coffers is curved and the author supposes that this was a modification applied to hide the coffers' imperfections when the ancient building was transformed into a church.

"The Racetrack Oval Frame Vault of Villa Borromeo in Cassano d'Adda", by Chiara Stanga, deals with the themes of the survey and geometric interpretation of a masonry vault made on the frame scheme defined by Guarini and widely used in northern Italy, in this example applied to plan, whose shape is a "racetrack oval", that is, one with two parallel sides and two semi-circles. The author, following a well-established scheme of analysis, integrates the results of direct survey and Structure from Motion (SfM) survey of the intrados and extrados surfaces of the vault. Then, for subsequent steps, she processes data acquisition for the realization of a point cloud and undertakes a geometric analysis and primitive extraction for the construction of an interpretative three-dimensional model, particularly useful for the understanding of construction techniques and structural behaviour. 


\section{Relationships Between Geometry and Architecture: Shapes, Materials, and Ornamentations}

The relationships between architecture and geometry are intertwined through the activity of conception, the choice of materials, the construction needs, and the definition of a decorative apparatus, often entrusted to workers, during the construction phase. The close link between the geometry of shapes, design, and perceptual aspects is therefore strongly influenced by what happens (often) after the moment of conception and which sometimes produces, depending on the case, outcomes that are very different from the original idea. Studies on complex vaulted systems cannot disregard these factors, which can determine the main character of a built architecture; materials, light, and decoration can emphasize and multiply the effectiveness of the original idea (even in its geometric aspects), depower or totally deny its essence, or even produce effects that overlap the built space, altering or enriching perception.

The contributions related to this topic deal with the following: lighting effects and perceptual factors in the Basilica of the Monastery of El Escorial, and geometric interpretation and virtual reconstruction of the illusory architecture painted on the vault of the Camera di Giove in Sassuolo.

Pilar Chías, Tomás Abad, Manuel De Miguel, and Paz Llorente, in "The Transparente in the Basilica of the Monastery of El Escorial", present a theme of great interest that links aspects related to the geometry of forms, geometry of light, and perceptual effects. The object studied is a small frescoed barrel vault behind the high altar that produces an effect calculated to coincide with certain times of day and feasts during the year, intensifying emotions and triggering various psychological effects in the spectator. The authors, by means of a laser scanner survey of the geometric characteristics of the space (interior and exterior) of the basilica and a study about the inclination of the sun's rays with respect to the window from which the Transparente takes and diffuses the light, present insights related to perceptual effects with respect to the positioning of the viewer and make evident some dimensioning errors in the original descriptions.

The interesting paper "The Illusory Architecture of the Camera di Giove in Sassuolo", by Michele Russo, Alessandra Marina Giugliano, and Laura Carnevali, develops research on survey and analysis of a vault and its quadratura painting in the Ducal Palace of Sassuolo. The methodology and workflow showcased by the authors (in particular with respect to management and validation of survey data) constitute one of the best practices in relation to this particular theme. The analysis and the digital reconstruction focus on the understanding of the geometric-mathematical relationships between the architecture, the vault, and the painting to elucidate, on the one hand, the painter's intentions, and on the other, the spatial relationships between real and ephemeral information in a typical Baroque example of the extension of spatial perception. 


\section{Investigation of the Relationships Between Geometry and Structure in Historicized Vaulted Systems}

The relationship between geometry and structure is an indissoluble bond because each has immediate effects on the other: a change in structure immediately determines a change in geometric characteristics, just as the definition of the geometry of space can determine very different construction methods and structural behaviours. Ranging from the macroscopic aspects of the shape to the minute geometric characteristics, the latest simulation and calculation tools support the research focused on this relationship, making it possible to verify or disprove design intuitions, compare structural solutions related to a given geometry (and vice versa), and parameterize the characteristics of a shape in order to identify the best structural performance.

The contributions related to this topic explore the shape grammar analysis applied to Utzon's process of vault ideation, the investigation on the stereotomy of conical vaults through digital tools, the problem of equal strength of largespan vaulted structures, and the structural behaviour of barrel and cross vaults in bricks subjected to imposed displacements.

“A Grammatical Note on Utzon's Vaults”, by Rizal Muslimin, analyses Jørn Utzon's process of vault ideation through the lens of shape grammar, from investigating the spherical schema's 'eureka' moment for the Sydney Opera House to interpreting the generation of vault schema in his other projects. The author maintains that understanding the ideation process that leads to the final schema is important in learning how to formulate a broader range of geometric principles for vault design. He discovers and demonstrates that most of the schemas of Utzon's vault can be generated with only a few rules and that the generated schema can produce various parts in the design. On the basis of the analysis carried out, the author concludes that Utzon seemed to be fully aware of the geometric mechanism ready to translate his intuition into an explicit representation of it for construction and communication purposes.

Paolo Borin, Alberto Longhin, Andrea Giordano, and Giovanna Xotta, in "From Scripting to Structural Computation of Conical Vaults" offer an original interpretation of stereotomy through digital tools, ranging from the shape's geometric generation to the study of structural behaviour. Moreover, they aim to deepen the relationship between the geometrical-mathematical features of an architectural surface and its structural-configurative properties through these tools. Extraordinary shapes that were the object of the analysis, such as trumpet squinches and conoidical vaults, can be produced by a generative rule. The scripting operation through Visual Programming Languages (VPL) becomes the management tool of the relationship between the geometry, configuration, and structural behaviour. In fact, the link between these three is offered by the study of static equilibrium of the vaults through the Thrust Network Analysis (TNA) as a computational method based on graphic and geometric procedures. The configurative and geometric analysis of vaults is paired with structural integrity to better manage historical buildings. 
The work by Dimitrije Nikolić and Vladimir Živaljević, "On the Modelling of Vaulted Structures of Equal Strength", deals with the problem of equal strength of large-span vaulted structures. This problem concerns two properties: the shape of the structure's midline (or midsurface) and the variation of thickness throughout the structure. The optimization of these structures leads to the so-called catenary of equal strength and the three-dimensional equivalent membrane of equal strength. The authors elaborate on the equilibrium analysis and analytical expressions that describe the resulting shapes and provide the visualization of the corresponding solutions as particular forms of large-span vaulted structures. They conclude that there is only one shape of such a structure's midsurface, whereby material properties affect only its size; size, however, has a theoretical limit. In addition, using the Finite Element Method (FEM), they consider various arch and dome sizes and materials and confirm the assumption about equal stress distribution within such structures. As the authors keenly observe, the form-finding problems can therefore be reconsidered within a framework of architectural design, and by combining a pure mathematical optimization approach with modern digital fabrication techniques, great architectural structures can be realized.

Marco Alforno, Fiammetta Venuti, and Alessia Monaco, in “The Structural Effects of Micro-Geometry on Masonry Vaults" conduct a very interesting in-depth study of the structural behaviour of barrel and cross vaults in brick subjected to imposed displacements as regards the different configurations of masonry equipment layout. The authors illustrate the two different approaches to structural behaviour of macroand micro-geometry and investigate the role of micro-geometry in the different types of equipment studied through a numerical simulation. The results are quite interesting and make it possible to validate some speculations found in technical literature.

In conclusion, a few words are necessary in order to thank all those who have contributed to this special issue of the Nexus Network Journal. We are truly grateful to editor-in-chief Kim Williams, who has followed the entire process, generously providing expertise, advice, and suggestions, and coordinating and organizing each phase of the work.

Special thanks go to the authors who responded to the call with a large number of excellent articles, presenting the results of studies and insights in accordance with the scientific aims of the journal and the topics proposed by us, from which it was difficult to choose. The selection was particularly severe: we received about forty papers, among which twenty-one were selected for publication. The number of essays published, which is almost double the number normally published in a single issue of the journal, attests to the great interest that the theme of complex vaulted systems arouses in scholars.

We also thank the committee of peer reviewers, assisted and coordinated by us. Their invaluable work allowed the authors to present their contributions in the best possible way and guaranteed a high standard of the papers presented here.

Publisher's Note Springer Nature remains neutral with regard to jurisdictional claims in published maps and institutional affiliations. 
Roberta Spallone architect and Ph.D. in "Drawing and Survey of Architectural Heritage", is Full Professor at the Politecnico di Torino, Department of Architecture and Design (DAD). She is a member of the School of Architecture, and currently teaches in the Laboratory of Drawing and Survey and Digital techniques of representation. She is on the Board of the Doctorate of Architectural and Landscape Heritage and director of the excellence Ph.D. course "Complex vaulted systems: geometry, design, construction". Her research focusses on the fields of history and criticism of architectural drawing, with particular attention to classic treatises on architecture and the art of fortification, and digital technologies for graphical analyses and reconstructive modeling. She is author of 180 publications, including both monographs and articles, and has participated as a speaker in many international conferences, including Nexus conferences in 2016 and 2018.

Marco Vitali earned a Ph.D. in "Drawing and Survey for the protection of the Housing stock and Territorial Heritage" from the Politecnico di Torino, where he is currently Associate Professor in the Department of Architecture and Design (DAD). He currently teaches in the Laboratory of Drawing and Survey, in the Bachelor in Architecture program, and the Representation project "Fundamentals of Descriptive geometry" in the degree program in Design and Visual communication. His research concerns the areas of architectural survey, urban and environmental survey, descriptive geometry and digital representation, fields in which he has published 90 works, including monographs and articles. He has presented papers at international conferences, including Nexus 2016 and 2018. 